\section{Comparison of Turfgrass Visual Quality Ratings with Ratings Determined Using a Handheld Optical Sensor}

\author{
Gregory E. Bell ${ }^{1}$, Dennis L. Martin, Kyungjoon Koh, \\ and Holly R. Han
}

ADDITIONAL INDEX WORDs. reflectance sensing, remote, NTEP, buffalograss, zoysiagrass, bermudagrass

SumMARY. Turfgrass performance can be assessed in terms of visual quality, but evaluators require training and may be distracted by many factors that affect accuracy and consistency. The objectives of this study were to assess a handheld optical sensor (GreenSeeker) for evaluating overall turfgrass quality in three turf species over two growing seasons, and to compare the combined time required for visual evaluation and data entry with the time required for the same functions using the handheld optical sensor. Visual quality ratings and sensor ratings were collected on schedules prescribed by the National Turfgrass Evaluation Program for the 2002 bermudagrass (Cynodon spp.), 2002 buffalograss (Bucbloe dactyloides), and 2002 zoysiagrass (Zoysia spp.) studies in 2003 and 2004. Use of the sensor reduced the time required to complete data collection and data entry by $58 \%$ compared with human visual evaluation. Of the three species tested, the bermudagrass evaluation had the strongest correlation between ratings collected by the human evaluator and the sensor [ $r=0.79$ in $2003(n=343), r=0.85$ in $2004(n=343)]$. The handheld optical sensor provided a consistent, objective evaluation of overall turfgrass quality and required less time than visual evaluation. The handheld optical sensor provides advantages for assessing turfgrass quality that cannot be realized by human evaluation, but the sensor alone is not sufficient for specific evaluations such as color, texture, or density that are routinely characterized by human evaluation.

$\mathrm{H}$ orst et al. (1984) studied visual evaluation methods common to turfgrass science and determined that visual evaluations among 10 human evaluators were inconsistent and could be considered inadequate. Assessing turfgrass features such as color, density, and overall quality by human visual evaluation is subjective and time consuming (Bell et al., 2002a; Trenholm et al., 1999a). In addition, visual evaluators may be distracted by mowing patterns, rating direction, cloudiness, shadows, and turf wetness (Krans and Morris 2007). These distractions sometimes make it difficult for evaluators to accurately discriminate turf responses or genetic variation. Consequently, turfgrass evaluators require training and experience to attain

\footnotetext{
Approved for publication by the Director, Oklahoma Agricultural Experiment Station.

Funding provided by the Oklahoma Turfgrass Research Foundation (grant no. AG-89-RS-140) and by The Oklahoma Agricultural Experiment Station (project no. OKLO 2392).

Department of Horticulture and Landscape Architecture, Oklahoma State University, Stillwater, OK 74078

${ }^{1}$ Corresponding author. E-mail: greg.bell@okstate.edu.
}

satisfactory proficiency in turfgrass quality evaluation.

Recently, optical sensing techniques have been introduced that measure the reflectance from turf canopies to determine turfgrass growth (Bell et al., 2004), wear tolerance (Trenholm et al., 1999a, 1999b), herbicide tolerance (Bell et al., 2000), and $\mathrm{N}$ fertility (Bell et al., 2002b, 2004; Trenholm et al., 2001). Bell et al. (2002a) demonstrated that optical sensing was not only effective for estimating turf color and percentage of living cover, but was equally efficient and more consistent for that purpose than visual evaluation of tall fescue (Festuca arundinacea) and creeping bentgrass (Agrostis stolonifera). The study also demonstrated that optical sensing results were not influenced by texture and that a combination of turfgrass color and turfgrass cover accounted for most of the variability in models used to predict sensor measurements from human evaluations. These results were further confirmed by Kenworthy et al. (2006) on bermudagrass. Bell et al. (2002a) reported that human evaluations of color or cover alone were not as closely related to sensor measurements as color and cover in combination.

In a former test of optical instruments, it was found that optical sensing required slightly more time and was more costly compared with human visual rating (Bell et al., 2002b). However, improvements in the processing speed of reflectance data instrumentation have made faster collection speeds attainable. At least one modern instrument, the GreenSeeker handheld sensor (NTech, Ukiah, CA) is faster to operate, less expensive (about $\$ 3500$ in 2006), and easier to use than the instruments tested earlier (Bell et al., 2002a; Trenholm et al., 1999a). The objectives of this study were to assess a handheld optical sensor for evaluating overall turfgrass quality in three turf species over two growing seasons, and to compare the time required of visual evaluation and data entry with the time required for the same functions using a handheld optical sensor.

\section{Materials and methods}

This study was conducted at the Oklahoma State University Turfgrass Research Center in Stillwater. Visual ratings and sensor ratings were collected on schedules prescribed by the National Turfgrass Evaluation Program (NTEP) in Beltsville, MD, for the 2002 bermudagrass ( 49 cultivars), 2002 zoysiagrass (20 cultivars), and 2002 buffalograss [10 cultivars + 'Cody' (a local standard)] trials during 2003 and 2004. NTEP is designed to develop and coordinate uniform evaluation trials of turfgrass cultivars and promising selections in the United States and Canada (NTEP, 2008).

Each of the NTEP trials was arranged in a randomized complete

\begin{tabular}{llll}
\hline $\begin{array}{l}\text { Units } \\
\begin{array}{l}\text { To convert U.S. to SI, } \\
\text { multiply by }\end{array}\end{array}$ & U.S. unit & SI unit & $\begin{array}{l}\text { To convert SI to U.S., } \\
\text { multiply by }\end{array}$ \\
\hline 0.3048 & $\mathrm{ft}$ & $\mathrm{m}$ & 3.2808 \\
2.54 & inch(es) & $\mathrm{cm}$ & 0.3937 \\
0.4536 & $\mathrm{lb}$ & $\mathrm{kg}$ & 2.2046 \\
1.6093 & $\mathrm{mph}$ & $\mathrm{km} \cdot \mathrm{h}^{-1}$ & 0.6214
\end{tabular}


block design with three replications. Plot sizes were $5 \times 5 \mathrm{ft}$ on the buffalograss trial, $6 \times 6 \mathrm{ft}$ on the zoysiagrass trial, and $6 \times 6 \mathrm{ft}$ on the bermudagrass trial. Mowing heights were $3.0,0.5$, and 0.5 inches on the buffalograss, zoysiagrass, and bermudagrass sites, respectively. Data were analyzed for NTEP reports using analysis of variance [ANOVA $(P<$ $0.05)$ ] with mean separation using Fisher's protected least significant difference [LSD $(P<0.05)]$. Visual evaluation by a human evaluator was determined on a 1 to 9 scale where 1 was very poor quality turf, 6 was minimally acceptable turf, and 9 was exceptional turf quality (Morris, 2004). A clipboard and paper were used to record visual ratings. The sensor ratings were made within 24 $\mathrm{h}$ of the visual ratings and were automatically recorded to a portable data analyzer (PDA).

The GreenSeeker handheld sensor was composed of four main parts: a sensor head, a telescoping tube, a PDA, and a control box. A single sensor was mounted to a telescoping pole that comprised the primary structure of the handheld. A rechargeable battery rested on the opposite end of the pole to provide power and counterbalance the weight of the sensor. The entire unit weighed approximately $11 \mathrm{lb}$. The unit was suspended from a shoulder strap that was adjustable for the comfort of the individual user. The sensor scanned an area that was $2 \mathrm{ft}$ wide perpendicular to the direction of travel and 0.375 inches long in the direction of travel. Reflectance data collection was by pulse rather than continuous scanning with samples taken at up to 900 samples per second. For this study, the sensor was programmed to collect at a relatively slow rate of 10 samples per second. Consequently, the unit collected 10 to 20 subsamples in a plot 6 $\mathrm{ft}$ long when moving at a normal (2-3 $\mathrm{mph}$ ) walking pace. The variation among these subsamples could provide an accurate, inverse quantitative measure of turf uniformity, but that was not the purpose of this study. The subsamples were computed as normalized difference vegetation indices (NDVI) and were stored on the PDA attached to the handheld unit. The NDVI is equal to a reflectance measurement usually in the near infrared region of the spectrum, in this case,
$780 \mathrm{~nm}$, minus a reflectance measurement usually in the red region of the spectrum, in this case, $660 \mathrm{~nm}$, divided by the sum of the same two measurements. Other vegetation indices have been developed and tested for use with turf and other plants, but NDVI is most common (Bell and Xiong, 2007).

To use the GreenSeeker sensor, the operator depressed a trigger to collect data and released the trigger when data collection for a single plot was complete. Each time the trigger was released and depressed, a new plot number was recorded and subsamples were assigned to the new plot number. The sensor head measured reflectance at about 660 and $780 \mathrm{~nm}$ generated by sensor integrated light emitting diodes and was unaffected by sunlight (Bell et al., 2002a). This integrated light source allows a sensor unit to work as effectively in shade or in the dark as it does in full sun. The NDVI were transferred directly from the PDA memory to a desktop computer in a format conducive for statistical analysis.

We hypothesized that the handheld optical sensor could provide faster, more accurate data collection than visual evaluation if certain assumptions were met. For example, it was assumed that the area of each trial that the sensor scanned was a subsample of the plot, and that this subsample represented the whole plot in terms of cultivar purity, maintenance inputs, and all turfgrass response characteristics of the target population. Also, it was assumed that the entire plot had no contamination or that the contamination could be identified and avoided by the sensor operator.

The time required for data collection and data entry to an Excel spreadsheet (Microsoft, Redmond, WA) in a format conducive for statistical analysis was measured and recorded for each rating event and each rating method to compare the speed and efficiency of visual rating and sensor rating. The time required for evaluation and analysis procedures that did not differ between sampling methods such as traveling to the data collection site, setting up a computer software spread sheet, etc. were not recorded or evaluated in this study therefore results are not consistent with the total time required for evaluation and analysis of an NTEP study. The total time required to evaluate an NTEP study is considerably longer than the time recorded here.

Statistical analyses were performed using SAS (version 8.1; SAS Institute, Cary, NC). Cultivar differences were determined by the ANOVA procedure as a randomized complete block design monthly and as a split plot in time for comparison of annual and overall results $(P<0.05)$. Rating date $\times$ cultivar interaction was ignored as would occur in a NTEP analysis. Mean separations were determined by Fisher's LSD $(P<0.05)$. Rating methods were compared statistically by linear correlation $(P<0.05$, $0.01,0.001$ ) and logically by comparing the mean separation of cultivars resulting from the use of each rating method.

\section{Results and discussion}

SPEED OF COLLECTION AND DATA ENTRY. Visual rating using the methodology of this study required a period 2.4 times longer than sensor rating to complete data collection and data entry (Table 1). Except for the bermudagrass trial, the time required for manual data entry did not differ substantially from the time required to download data from the PDA used to record sensor results. However, manual keyboard entry from rating sheets to Excel spreadsheets required a thorough examination for errors during or following entry. The data transfer from the sensor PDA to computer only required that the user check to make sure that the correct number of plots had been recorded for each row and that the NDVI results were in the range consistent with turf reflectance. The subsamples collected by sensor were recorded by plot to a file in spreadsheet format and could be used to determine uniformity. These subsamples were also automatically averaged and stored by plot in a second file that was used to transfer results by plot to a common spreadsheet following data collection. Sensor evaluation simplified data assessment and did not have the errors common to manual data entry. Manual keyboard entry and verification was faster than sensor data entry for the smallest trial, buffalograss, but was slower for the largest trial, bermudagrass (Table 1). Consequently, 
Table 1. Time required to evaluate the 2002 National Turfgrass Evaluation Program (Beltsville, MD) buffalograss, zoysiagrass, and bermudagrass studies using visual rating ${ }^{\mathrm{z}}$ and normalized difference vegetation index (NDVI) ${ }^{\mathrm{y}}$ collected using the GreenSeeker handheld sensor for 7 months in 2003 and 7 months in 2004.

\begin{tabular}{|c|c|c|c|c|c|c|c|c|c|c|c|c|c|c|}
\hline & \multicolumn{6}{|c|}{2003} & \multicolumn{7}{|c|}{2004} & \multirow[b]{2}{*}{ Overall } \\
\hline & May & June & July & Aug. & Sept. & Oct. & Apr. & May & June & July & Aug. & Sept. & Oct. & \\
\hline & \multicolumn{14}{|c|}{ Evaluation time (min) } \\
\hline $\begin{array}{l}\text { Visual data } \\
\text { collection }^{x}\end{array}$ & 8 & 5 & $\mathrm{~N} / \mathrm{A}^{\mathrm{t}}$ & 10 & 11 & 8 & 12 & 5 & 11 & 7 & 6 & 8 & 8 & 8 \\
\hline $\begin{array}{l}\text { Visual keyboard } \\
\text { entry }^{\mathrm{w}}\end{array}$ & 5 & 4 & $\mathrm{~N} / \mathrm{A}$ & 5 & 4 & 5 & 3 & 3 & 4 & 3 & 3 & 3 & 3 & 4 \\
\hline $\begin{array}{l}\text { Sensor download } \\
\text { entry }^{\mathrm{u}}\end{array}$ & 6 & 5 & $\mathrm{~N} / \mathrm{A}$ & 6 & 6 & 5 & 5 & 6 & 5 & 5 & 5 & 5 & 5 & 5 \\
\hline \multicolumn{15}{|l|}{ Zoysiagrass } \\
\hline Data collect & $\mathrm{N} / \mathrm{A}$ & 11 & 11 & 10 & 12 & 10 & 11 & 14 & 16 & 12 & $\mathrm{~N} / \mathrm{A}$ & 10 & 11 & 12 \\
\hline \multirow{4}{*}{$\begin{array}{l}\text { Bermudagrass } \\
\text { Data collect } \\
\text { Keyboard entry } \\
\text { Sensor collect } \\
\text { Sensor download }\end{array}$} & $\mathrm{N} / \mathrm{A}$ & 20 & 17 & 15 & 17 & 21 & 22 & 21 & 28 & 16 & 14 & 16 & 14 & 18 \\
\hline & $\mathrm{N} / \mathrm{A}$ & 7 & 7 & 8 & 9 & 12 & 16 & 9 & 8 & 12 & 8 & 9 & 10 & 10 \\
\hline & $\mathrm{N} / \mathrm{A}$ & 5 & 5 & 5 & 5 & 5 & 5 & 5 & 5 & 5 & 5 & 5 & 5 & 5 \\
\hline & $\mathrm{N} / \mathrm{A}$ & 5 & 5 & 5 & 6 & 5 & 5 & 6 & 6 & 5 & 6 & 5 & 5 & 5 \\
\hline
\end{tabular}

${ }^{z}$ Visual ratings were assigned on a 1 to 9 scale where $1=$ poor quality turf, 6 = minimally acceptable turf, and $9=$ exceptional turf quality.

yDVI $=(780-660 \mathrm{~nm}$ reflectance $) \div(780+660 \mathrm{~nm}$ reflectance $)$ collected using a GreenSeeker handheld optical sensor $(\mathrm{NTech}$ Industries, Ukiah, CA $)$.

${ }^{x}$ Ratings were collected by a human evaluator who wrote her visual assessment of each plot on paper as she worked her way across the study.

wKeyboard entry included transferring plot ratings from paper to digital media and double-checking the entries.

"Sensor data were recorded to a personal digital assistant when the operator pressed a button as he entered a plot and released it as he left the plot while proceeding at a speed of $\approx 2.5 \mathrm{mph}\left(4.02 \mathrm{~km} \cdot \mathrm{h}^{-1}\right)$.

"Download included transferring digital files from the personal digital assistant to a desktop computer, entering the file into a data spreadsheet, and checking to make sure that the correct number of plots had been recorded.

${ }^{\mathrm{t}} \mathrm{N} / \mathrm{A}$, not available, was reported when specific data were not collected on a particular date.

Table 2. Pearson correlation coefficients ( $r$ ) resulting from linear correlation of normalized difference vegetation index $(\mathrm{NDVI})^{\mathrm{z}}$ and visual quality ${ }^{\mathrm{y}}$ for buffalograss monthly $(\mathrm{n}=11)$, annually $(\mathrm{n}=77)$, and overall $(\mathrm{n}=154)$, zoysiagrass monthly $(n=20)$, annually $(n=140)$, and overall $(n=280)$, and bermudagrass monthly $(n=49)$, annually $(n=343)$, and overall $(n=686)$ during the 2003 and 2004 growing seasons in Stillwater, OK.

\begin{tabular}{|c|c|c|c|c|c|c|c|c|c|}
\hline & Apr. & May & June & July & Aug. & Sept. & Oct. & Annual & Overall \\
\hline & \multicolumn{9}{|c|}{ Pearson correlation coefficient $(r)$} \\
\hline \multicolumn{10}{|c|}{ Buffalograss } \\
\hline 2004 & $0.73^{*}$ & $0.14 \mathrm{NS}$ & $0.69 *$ & $0.79 * *$ & $0.20 \mathrm{NS}$ & $0.90 * * *$ & $0.46 \mathrm{NS}$ & $0.65 * * *$ & \\
\hline \multicolumn{10}{|c|}{ Zoysiagrass } \\
\hline 2003 & $0.81 * * *$ & $0.90 * * *$ & $0.37 \mathrm{NS}$ & $0.74 * * *$ & $0.35 \mathrm{NS}$ & $0.47^{*}$ & $0.76 * * *$ & $0.66 * * *$ & $0.66 * * *$ \\
\hline 2003 & $0.87 * * *$ & $0.82 * * *$ & $0.37 * *$ & $0.26 \mathrm{NS}$ & $0.52 * * *$ & $0.81 * * *$ & $0.63 * * *$ & $0.79 * * *$ & $0.80 * * *$ \\
\hline 2004 & $0.94 * * *$ & $0.80 * * *$ & $0.81^{* * *}$ & $0.62 * * *$ & $0.26 \mathrm{NS}$ & $0.69 * * *$ & $0.71 * * *$ & $0.85 * * *$ & \\
\hline
\end{tabular}

${ }^{\mathrm{z}} \mathrm{NDVI}=(780 \mathrm{~nm}$ reflectance $-660 \mathrm{~nm}$ reflectance $) \div(780 \mathrm{~nm}$ reflectance $+660 \mathrm{~nm}$ reflectance $)$ collected using a GreenSeeker handheld optical sensor $(\mathrm{NTech}$ Industries, Ukiah, CA).

VVisual ratings were assigned on a 1 to 9 scale where $1=$ poor quality turf, $6=$ minimally acceptable turf, and $9=$ exceptional turf quality.

Ns, ${ }^{*}, * *{ }^{* *}$ tests of linear correlation of visual rating and NDVI were not significant (Ns) or were significant at $P<0.05, P<0.01$, or $P<0.001$, respectively.

where large trials or multiple trials are conducted, the sensor method is likely to save considerable time during data entry. The sensor method was always faster for data collection, regardless of circumstances or conditions that occurred during this study. In this trial of small (30 plots), medium (60 plots), and large (147 plots) studies, the sensor method saved an average of $33 \mathrm{~min}$ each time data were collected and recorded compared with visual rating.

SENSOR RATING COMPARED WITH VISUAL RATING. According to their web site, "the NTEP is designed to develop and coordinate uniform evaluation trials of turfgrass cultivars and promising selections in the United States and Canada. Test results can be used by national companies and plant breeders to determine the broad picture of the adaptation of a cultivar. Results can also be used to determine if a cultivar is well adapted to a local area or level of turf maintenance" (NTEP, 2008). Consequently, the 


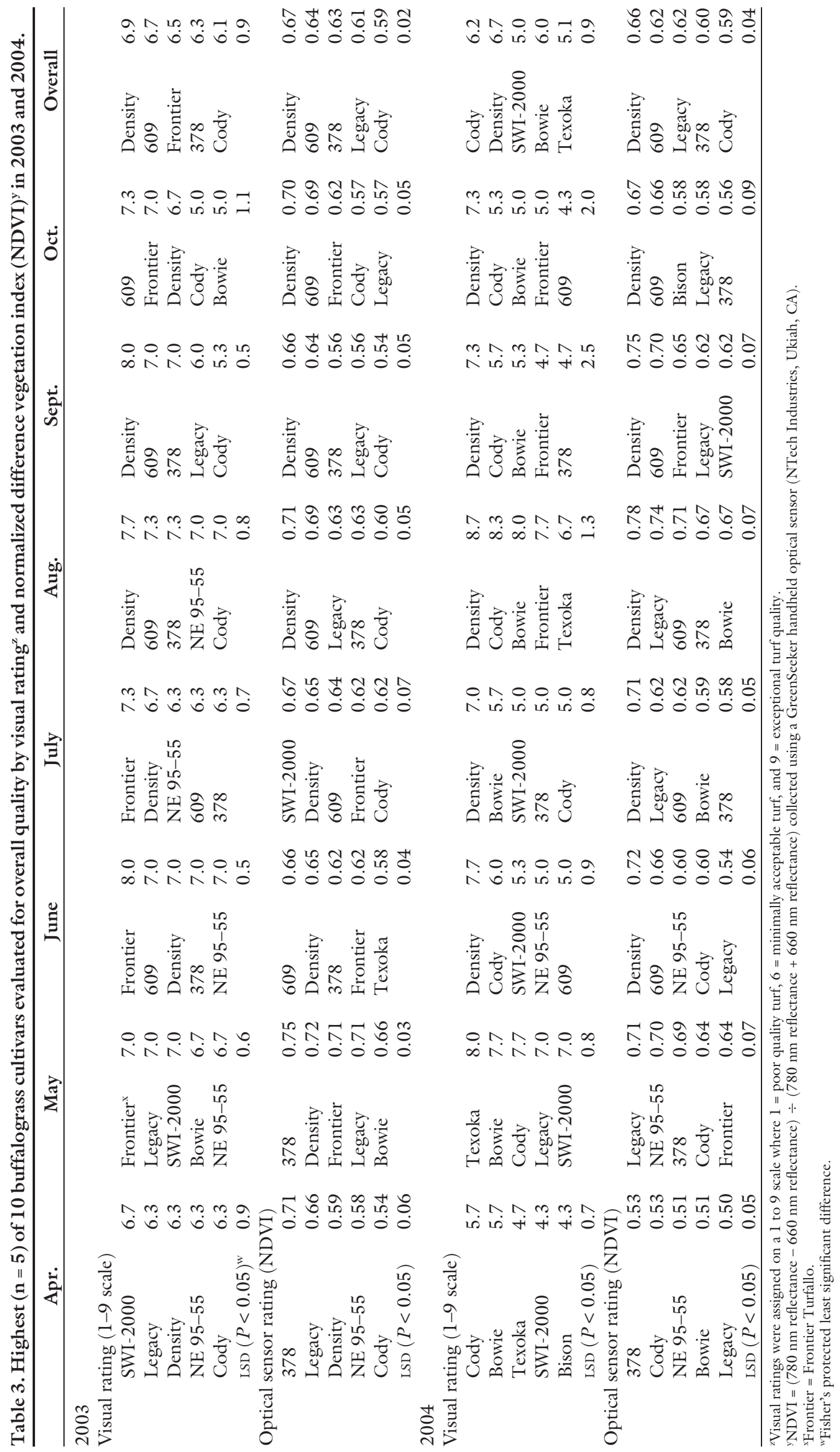




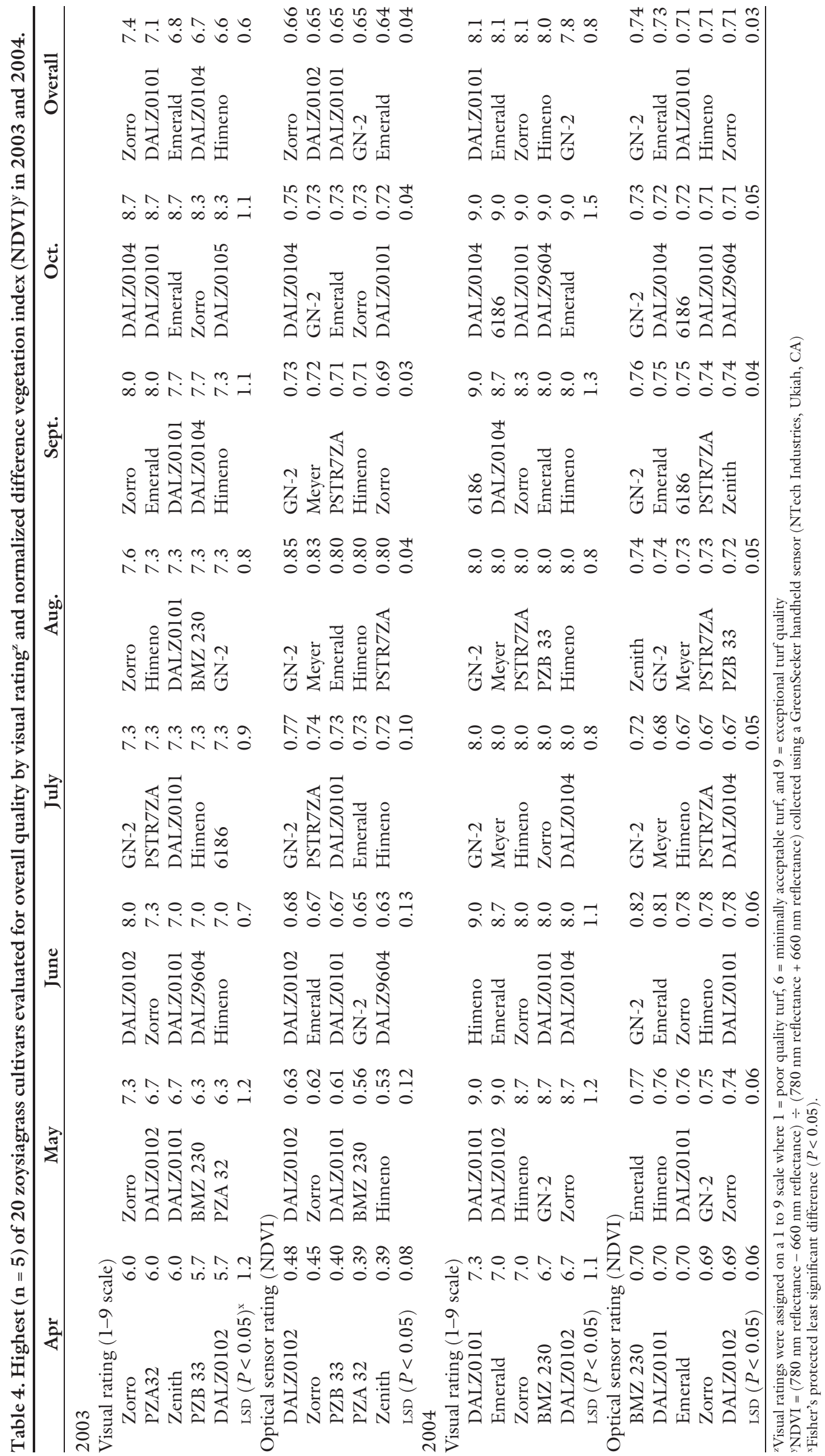




\section{Research Reports}

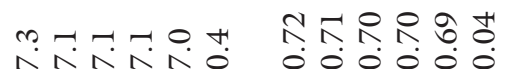

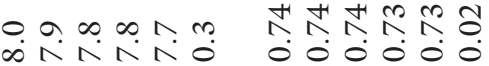

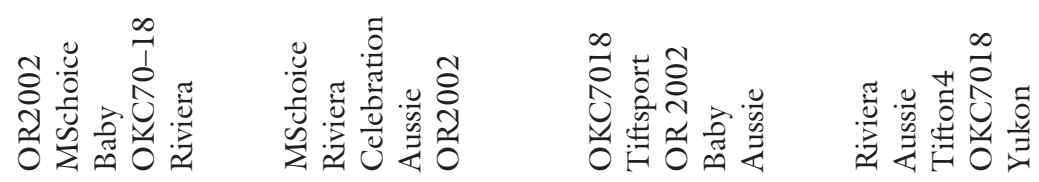

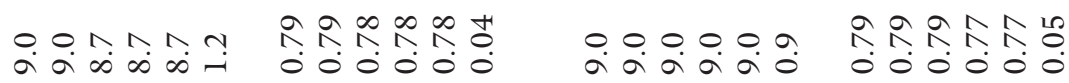

穿苛

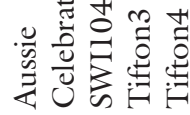

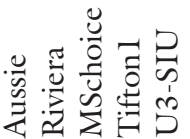

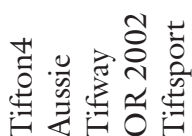

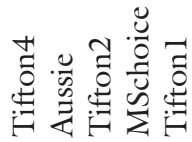

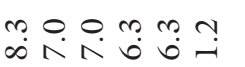

중ㅇㅇㅇ

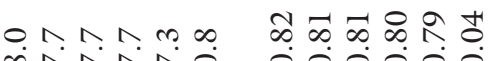

矛

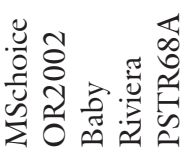

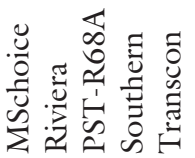

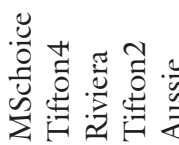

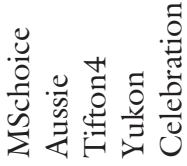

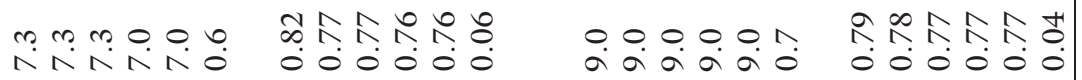

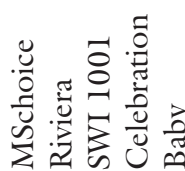

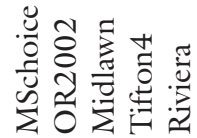

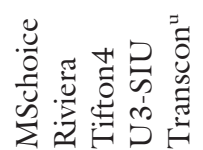

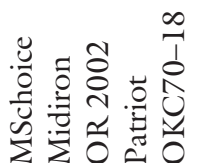

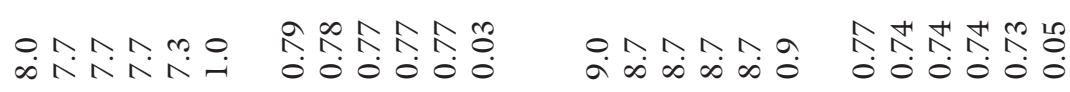

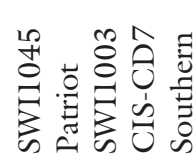

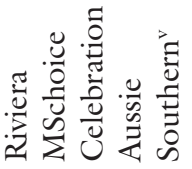

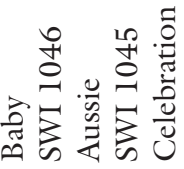

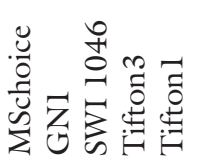

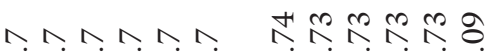

$\wedge O 0 \wedge \wedge \sigma$

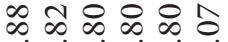

ñNลNO

000000

$\infty \infty \infty \wedge \sim$

00000

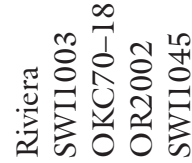

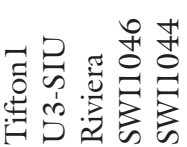

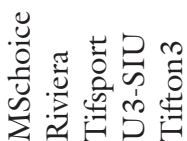

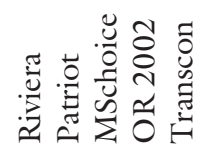

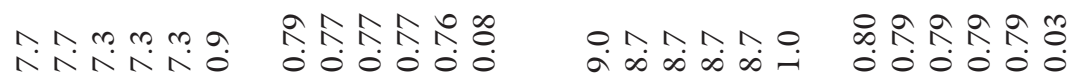

窟

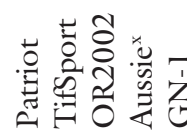

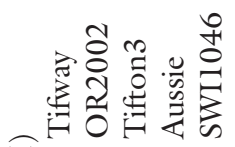

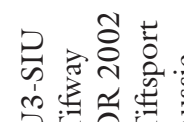

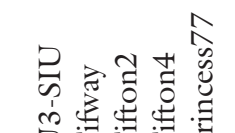

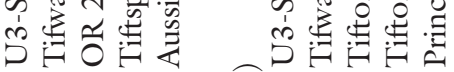

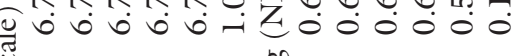

$\underbrace{}_{0} \infty \begin{array}{ll}0 \\ 0\end{array}$

$\stackrel{i}{=}$

\section{政}

.

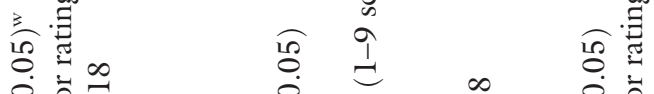


best-performing cultivars in any given trial are of particular interest to consumers in that geographic area. Mean separations (LSD at $P<0.05$ ) are used to rank the performance of cultivars at each site and nationwide. Presumably, the top-ranking cultivars at a site are those with good to excellent aesthetic characteristics and the best adapted to that region. When the cultivars studied were compared statistically over the study period (both years) according to visual rating, the highest ranking buffalograss group consisted of only one cultivar, the top zoysiagrass group consisted of four cultivars, and the top bermudagrass group contained five cultivars. Consequently, it was deemed that a comparison of the five highest-ranking cultivars of each species according to visual rating and according to NDVI would be a good indication of their compatibility for the region studied and would provide adequate information to compare the two rating methods.

There were significant $(P<0.001)$ linear correlations between sensor measurements and visual ratings for each species during each season (Table 2). Among the species tested, the correlations of sensor evaluation and human evaluation were weakest for buffalograss in 2003 and 2004. Although the buffalograss correlations were relatively weak, the two cultivars ranked highest were the same in 2003 regardless of rating method (Table 3 ).

In 2004, the buffalograss cultivar Density was scored lowest (data not shown) for the first 2 months and highest for the remaining months according to visual rating (Table 3 ). 'Density' was also ranked highest for the remaining months according to the sensor. Overall, 'Density' ranked highest in sensor and visual rating in 2003 and was in the top two for both rating methods in 2004. In 2003, four of the top five buffalograss cultivars according to visual rating were also in the top five according to NDVI. In 2004, visual rating ranked 'Bowie' as one of the top three cultivars, but the sensor ranked 'Bowie' seventh highest $(\mathrm{NDVI}=0.57)$. The sensor ranked '609' in the top group, but visual rating ranked ' 609 ' lower (visual rating $=4.9$ ). Clearly, the sensor ratings did not match those of an individual evaluator with perfect consistency. In 2003 and 2004, there was widespread weed contamination observed in the buffalograss trial that resulted in the weakest correlations between methods among species. The human evaluator could speciate the weeds present, but the sensor operator had difficulty avoiding the widespread contamination. It is not known which rating system was the most accurate but in this case of severe contamination, it was probably human evaluation.

Zoysiagrass ratings indicated significant $(P<0.001)$ moderately strong correlations between sensor and visual ratings (Table 2). In 2003 and 2004, the top five cultivars in April were the same regardless of rating method (Table 4). In 2003, 'Zorro' ranked highest overall using both rating methods (Table 4 ). Of the top five cultivars in 2003, three were the same regardless of rating method. Overall in 2004, five of the top five cultivars were the same according to sensor and visual rating (Table 4). The ratings in August and September resulted in the weakest correlations between the sensor and visual rating compared with other months in both years (Table 2). This was expected because according to mean separations, cultivar differences were rare during those months compared with other months. Nonetheless, at least two of the top five cultivars were common to sensor and visual ratings during August and September.

The bermudagrasses had the best correlations between rating methods among the three species (Table 2). For instance, the Apr. 2004 rating separated the same top five cultivars in the same quantitative order, regardless of rating method (Table 5). During the summer months (June, July, and Aug. 2003; July and Aug. 2004), the correlations were much weaker than the early and late months (April, May, September, and October). The cultivar Aussie Green was ranked relatively poor but acceptable by visual rating (rating $=6.7$ ) in July 2003 but was ranked as one of the top five cultivars by the sensor (Table 5 ). 'Midiron' was visually rated as a top cultivar in Aug. 2004 but was ranked second lowest according to the sensor (NDVI = 0.63). The research of Horst et al. (1984) demonstrated that the ratings of individual visual evaluators compared poorly. Bell et al. (2002a) indicated that optical sensor ratings were highly comparable on a day-today basis and were more consistent than individual evaluators. Although it is difficult to determine which rating system is most accurate, optical sensing has proved to be the most consistent. A comparison of average sensor ratings with the average of a large group, perhaps 30 or more evaluators, made at about the same time on the same study may be needed to determine if sensor ratings compare closely with the true measure of turf quality, aesthetic value. A project of that magnitude would require a national or international effort and is beyond the scope of this article.

\section{Conclusions}

Several quantitative rating devices have been tested for use in turfgrass quality evaluation. These devices include digital cameras (Karcher and Richardson, 2005) spectroradiometers (Bell et al., 2004), multispectral devices (Raikes and Burpee, 1998), optical sensors (Park et al., 2005), and others. These devices have not been widely used probably because they were complicated, required long periods to assess data, required relatively high initial expenditures, and/or required device alterations and updates. However, the GreenSeeker handheld sensor used in this study was relatively inexpensive and required less total combined time for data collection and entry than visual evaluation.

Visual evaluations are not consistent among evaluators (Horst et al., 1984). Evaluators may not even be consistent among themselves on a day-to-day basis (Bell et al., 2002a). However, optical sensors are consistent among users and consistent from day to day (Bell et al., 2002a). The handheld sensor was very stable and did not require routine maintenance, update, and recalibration. Training personnel to use the handheld sensor, including data entry, was accomplished effectively in less than 60 min. Training a visual evaluator generally requires a period of hours or days and a period of months before the trainee becomes proficient.

An optical sensor such as the GreenSeeker handheld could be used as a supplement to visual evaluation for a baseline comparison of individual 
evaluators. Using this baseline comparison, the visual evaluations could be accurately compared among sites. Based on the results of this study and others, optical sensing could also be used as a measure of overall turfgrass quality or could be used as an alternative system on selected rating dates. Turfgrass breeders could use sensor ratings of turfgrass quality for fast, quantitative screening of germplasm. According to these results and those of previous research, turfgrass researchers could use sensor ratings as a quantitative measure of turfgrass response to treatments, damage, or disease infection.

Although it may be possible for a human evaluator to save time and labor using voice recorders or portable computerized devices, the typical evaluation method, manual recording of ratings to paper and transfer of ratings to digital storage via keyboard entry, was labor intensive and time consuming compared with quantitative data collection and transfer using the handheld optical sensor. Correlations of sensor ratings and visual ratings resulted in overall correlation coefficients that ranged from 0.59 to 0.80 , depending on species. However, sensor ratings and visual ratings generally identified the same cultivars within each species as exceptionally high in overall turfgrass quality. In this study, the data collected using the GreenSeeker handheld optical sensor to determine turfgrass quality compared well with that collected by a human visual evaluator and required considerably less time for data collection and entry.

\section{Literature cited}

Bell, G.E. and X. Xiong. 2007. The history, role, and potential of optical sensing for practical turf management, $\mathrm{p}$. 641-658. In: M. Pessarakli (ed.). Handbook of turfgrass management and physiology. CRC Press, Boca Raton, FL.

Bell, G.E., B.M. Howell, G.V. Johnson, W.R. Raun, J.B. Solie, and M.L. Stone. 2004. Optical sensing of turfgrass chlorophyll content and tissue nitrogen. HortScience 39:1130-1132.

Bell, G.E., D.L. Martin, R.M. Kuzmic, M.L. Stone, and J.B. Solie. 2000. Herbicide tolerance of two cold-resistant bermudagrass cultivars determined by visual assessment and vehicle-mounted optical sensing. Weed Technol. 14:635-641.

Bell, G.E., D.L. Martin, S.G. Wiese, D.D. Dobson, M.W. Smith, M.L. Stone, and J.B. Solie. 2002a. Vehicle-mounted optical sensing: An objective means for evaluating turfgrass quality. Crop Sci. 42:197-201.

Bell, G.E., D.L. Martin, M.L. Stone, J.B. Solie, and G.V. Johnson. 2002b. Turf area mapping using vehicle-mounted optical sensors. Crop Sci. 42:648-651.

Horst, G.L., M.C. Engelke, and W. Meyers. 1984. Assessment of visual evaluation techniques. Agron. J. 76:619-622.

Karcher, D.E. and M.D. Richardson. 2005. Batch analysis of digital images to evaluate turfgrass characteristics. Crop Sci. 45:1536-1539.

Kenworthy, K.E., C.M. Taliaferro, B. Carver, J.A. Anderson, D.L. Martin, and G.E. Bell. 2006. Genetic variation in Cynodon transvaalensis Burtt-Davy. Crop Sci. 46:2376-2381.

Krans, J.V. and K. Morris. 2007. Determining a profile of protocols and stand- ards used in the visual field assessment of turfgrasses: A survey of National Turfgrass Evaluation Program-sponsored university scientists. Online. Appl. Turfgrass Sci. doi: 10.1094/ATS-2007-1130-01-TT.

Morris, K. 2004. A guide to NTEP turfgrass ratings. 27 Oct. 2008. <http://www. ntep.org/reports/ratings.htm\#quality>.

National Turfgrass Evaluation Program. 2008. National Turfgrass Evaluation Program. 27 Oct. 2008. <http://www.ntep. $\operatorname{org} />$.

Park, D.M., J.L. Cisar, D.K. McDermitt, K.E. Williams, J.J. Haydu, and W.P. Miller. 2005. Using red and infrared reflectance and visual observation to monitor turf quality and water stress in surfactant-treated bermudagrass under reduced irrigation. Intl. Turfgrass Soc. Res. J. 10:115-120.

Raikes, C. and L.L. Burpee. 1998. Use of multispectral radiometry for assessment of rhizoctonia blight in creeping bentgrass. Phytopathology 88:446-451.

Trenholm, L.E., R.N. Carrow, and R.R. Duncan. 1999a. Relationship of multispectral radiometry data to qualitative data in turfgrass research. Crop Sci. 39:763-769.

Trenholm, L.E., R.N. Carrow, and R.R. Duncan. 2001. Wear tolerance, growth, and quality of seashore paspalum in response to nitrogen and potassium. HortScience 36:780-783.

Trenholm, L.E., R.R. Duncan, and R.N. Carrow. 1999b. Wear tolerance, shoot performance, and spectral reflectance of seashore paspalum and bermudagrass. Crop Sci. 39:1147-1152. 